\title{
Endometrial osseous metaplasia: clinicopathological study of a case and literature review
}

\author{
Ramya T. ${ }^{*}$, Chitra T.V. ${ }^{1}$, Poornima C. ${ }^{1}$, Anjana B. ${ }^{2}$ \\ ${ }^{1}$ Department of Obstetrics and Gynaecology, ${ }^{2}$ Department of Pathology, PSG Institute of Medical Sciences \& \\ Research, Coimbatore-641004, India \\ Received: 1 October 2013 \\ Accepted: 11 October 2013 \\ *Correspondence: \\ Dr. Ramya T, \\ E-mail: ramya.t2003@gmail.com \\ (C) 2013 Ramya T et al. This is an open-access article distributed under the terms of the Creative Commons Attribution \\ Non-Commercial License, which permits unrestricted non-commercial use, distribution, and reproduction in any \\ medium, provided the original work is properly cited.
}

\begin{abstract}
Endometrial ossification is a rare clinical condition related to menstrual disturbances and infertility. Its etiology and pathogenesis are controversial. The commonly accepted hypothesis is that ossification represents retained fetal bones following spontaneous or therapeutic abortion suggesting enchondral ossification. It can also be due to transformation of mesenchymal tissue to bone in response to chronic inflammation.
\end{abstract}

We present one such case in a 41 year old woman who presented with menorrhagia and dysmenorrhoea following induced abortion 16 years back at 12 weeks of gestation. The patient underwent hysterectomy. We also present a literature review.

Keywords: Osseous metaplasia, Endometrium, Hysterectomy

\section{INTRODUCTION}

Endometrial osseous metaplasia is an uncommon clinical entity with the presence of immature or mature bone in the endometrium. Nearly 80 cases have been reported in the world literature and very few cases from India. In most of the reported cases, the condition followed an abortion and patients presented with infertility.

The commonly proposed theories for endometrial osseous metaplasia are as follows: heterotropia, dystrophic calcification, metastatic calcification, prolonged estrogenic therapy after abortion and retained fetal bone.

\section{CASE REPORT}

A 41 year old female patient presented to the gynecology outpatient department with complaints of menorrhagia and dysmenorrhoea following abortion by dilatation and curettage at 12 weeks of gestational age.
The evacuation was done 16 years ago. Menorrhagia and dysmenorrhoea have increased in severity for the past 4 years. It was not responding to hormonal or non hormonal treatment.

The patient had two uneventful normal vaginal deliveries following which she had an induced abortion. She underwent sterilization few months later. Patient had endometrial curettage for her complaints two years back, the reports of which were unavailable. There was no relief of symptoms after the procedure. Ultrasound pelvis was done.

Uterus was $8.5 \times 4.6 \times 5.6 \mathrm{~cm}$. Endometrium was thin. A linear hypoechoeic area in the lower part of anterior myometrium measuring $2.1 \mathrm{~cm}$ was seen. Both ovaries were normal.

Patient was advised to undergo diagnostic hysteroscopy and then to plan further management. Inspite of the above 
suggestion patient insisted on hysterectomy and underwent the same uneventfully.

Macroscopically the lower part of the endometrial cavity showed yellow- brown bony material on aggregate measured $2 \mathrm{~cm}$ across, lying freely within the cavity.

The hemotoxylin and eosin stained paraffin sections showed trabeculae of woven bone. The endometrium was proliferative with focal chronic endometritis.

A histological diagnosis of osseous metaplasia of endometrium was made.

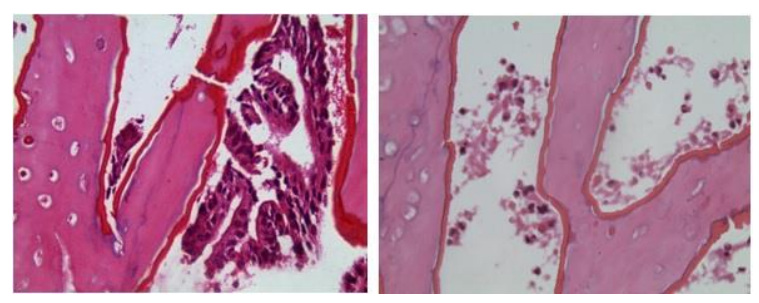

Figure 1: Histopathology images of the endometrium showing osseous metaplasia.
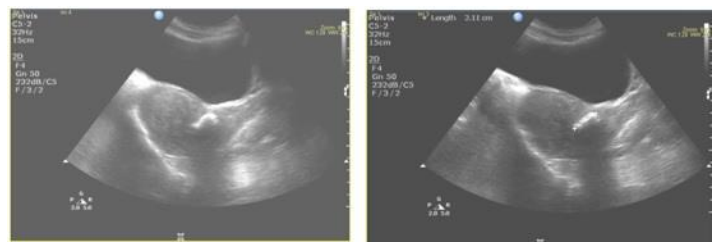

Figure 2: Ultrasound images showing the hyperechoic lesion.

\section{DISCUSSION}

Ossification of endometrium is a rare clinical condition. It is also referred to as ectopic intrauterine bone and heterotropic intrauterine bone. ${ }^{6,13,14}$ Ossification is also reported in the cervix, the ovary and the vagina. ${ }^{3,4,5,12}$

Common complaints are menstrual irregularities, pelvic pain, dyspareunia, secondary infertility and vaginal discharge. Shroff et al described a case of endometrial ossification in a woman presenting with primary infertility. ${ }^{11}$ Our patient had undergone sterilization and her complaints were mainly menstrual.

Majority of patients are in the reproductive age group with history of first trimester abortion either therapeutic or spontaneous and have normal menstrual cycles in the post abortive period.

The time interval between the antecedent abortion and the detection of endometrial ossification varies from 8 weeks to 14 years in the reproductive age group. ${ }^{8}$ In our case, the abortion was 16 years ago. Endometrial ossification has also been described in a 62 year old postmenopausal woman who underwent abortion 37 years ago. ${ }^{6}$
Heterotropia, dystrophic calcification and ossification of post abortive endometritis, metastatic calcification, metaplasia in healing tissue, prolonged estrogenic therapy after abortion and retained fetal bone are the proposed theories.9,10,12,13,14 Most authors opine that the bone formed is a result of metaplasia of endometrial stromal cells into osteoblastic cells that produce bone in the endometrium. ${ }^{6,11,12}$

Post abortive chronic endometritis stimulates the release of superoxide radicals and tumor necrosis factor from the inflammatory cells. ${ }^{8}$ Long term exposure of superoxide radicals and tumor necrosis factor on multipotent stromal cells in patients with deficient superoxide dismutase activity in the endometrium leads to metaplasia of the stromal cells into osteoblastic cells.

A case of endometrial ossification in a patient who was taking high dose of calcium and vitamin D for a long time has been reported. ${ }^{2}$ In our country endometrial tuberculosis should be ruled out as a case of calcification and ossification. ${ }^{11}$

In the past a series of curettage was advocated for the removal of the bone from the endometrium. Recently hysteroscopic removal of bone under ultrasonographic guidance have been recommended as it gives good visualization and helps in complete removal of the bony spicules that may be embedded in the myometrium. ${ }^{1,7,8}$

Bone in the endometrium can act as a foreign body and might cause menstrual irregularities and prevent conception. Its complete removal restores fertility and improves menstrual symptoms. , $^{8,13}$

\section{CONCLUSION}

Endometrial ossification is an uncommon but treatable condition in which intrauterine bone causes menstrual irregularities, pain, vaginal discharge and might delay conception. Chronic endometritis evokes metaplastic changes in the pluripotent endometrial stromal cells changing them into osteoblastic cells that lay down bone. Complete removal of the bony spicules from the endometrial cavity by hysteroscopy under ultrasonographic guidance regains fertility and cures menstrual symptoms.

\section{REFERENCES}

1. Cayuela E, Perez-Medina T, Vilanova J, et al. True osseous metaplasia of the endometrium: the bone is not from a fetus. Fertil Steril. 2009;91:1293.

2. Adamson NE., Jr Sommers SC. Endometrial ossification; Report of two cases. Am J Obstet Gynecol. 1954;67:187-90.

3. Landim FM, Tavares JM, de Melo Braga DN et al. Vaginal osseous metaplasia. Arch Gynecol Obstet. 2009;279:381-4. 
4. Campo S, Campo V, Zannoni GF, et al. Simultaneous ovarian and endometrial osseous metaplasia: A case report. J Reprod Med. 2007;52:241-2.

5. Bedaiwy MA, Goldberg JM, Biscotti CV. Recurrent osseous metaplasia of the cervix after loop electrosurgical excision. Obstet Gynecol. 2001;98:968-70.

6. Shimizu M, Nakayama M. Endometrial ossification in a postmenopausal woman. J Clin Pathol. 1997;50:171-2.

7. Coccia ME, Becattini C, Bracco GL, et al. Ultrasound-guided hysteroscopic management of endometrial osseous metaplasia. Ultrasound Obstet Gynecol. 1996;8:134-6.

8. Bahceci M, Demirel LC. Osseous metaplasia of the endometrium: a rare cause of infertility and its hysteroscopic management. Hum Reprod. 1996;11:2537-9.

9. Waxman M, Moussouris HF. Endometrial ossification following an abortion. Am J Obstet Gynecol. 1978;130:587-8.
10. Acharya U, Pinion SB, Parkin DE, et al. Osseous metaplasia of the endometrium treated by hysteroscopic resection. $\mathrm{Br} \mathrm{J}$ Obstet Gynaecol. 1993;100:391-2.

11. Shroff CP, Kudterkar NG, Badhwar VR. Endometrial ossification-- report of three cases with literature review. Indian J Pathol Microbiol. 1985;28:71-4.

12. Bhatia NN, Hoshiko MG. Uterine osseous metaplasia. Obstet Gynecol. 1982;60:256-9.

13. Dutt S. Endometrial ossification associated with secondary infertility. $\mathrm{Br} \mathrm{J}$ Obstet Gynaecol. 1978;85:787-9.

14. Hsu C. Endometrial ossification. $\mathrm{Br} \mathrm{J}$ Obstet Gynaecol. 1975;82:836-9.

DOI: $10.5455 / 2320-1770 . i j r \operatorname{cog} 20131251$

Cite this article as: Ramya T, Chitra TV,

Poornima C, Anjana B. Endometrial osseous metaplasia: clinicopathological study of a case and literature review. Int J Reprod Contracept Obstet Gynecol 2013;2:719-21. 